\title{
Olhares sobre Ouro Preto: da patrimonialização ao cenário turístico
}

An overview on Ouro Preto: from patrimonialization to tourism scene
Miradas sobre Ouro Preto: de la patrimonialización al escenario turístico

Ana Laura Assumpção

Instituto de Arquitetura e Urbanismo da Universidade de

DOI: https://doi.org/10.18472/cvt.19n1.2019.1354

São Paulo (USP), Brasil

Redalyc: http://www.redalyc.org/articulo.oa?

alauraassumpcao@gmail.com

Paulo César Castral

Instituto de Arquitetura e Urbanismo da Universidade de

São Paulo (USP), Brasil

pcastral@sc.usp.br

Recepção: 03 Novembro 2016

Aprovação: 24 Agosto 2018

\section{Resumo:}

Ouro Preto, que se conhece hoje, foi adquirindo importância ao longo da história do Brasil. A imagem de cidade tomou proporções que extrapolam o âmbito histórico-social, tomando o cenário turístico como o grande enfoque. Dentro desse percurso há dois acontecimentos que merecem destaque aqui: ter sido o palco das discussões acerca do caráter nacional brasileiro, iniciado no começo do século XX com os modernistas, e também ter se evidenciado pela formação do turismo, consolidado a partir da segunda metade do século XX. Diante disso, a intenção do presente estudo foi analisar as mudanças ocorridas nas representações de Ouro Preto nesses dois momentos. Para o primeiro período, foram escolhidas as pinturas do artista Guignard e os desenhos do Guia de Ouro Preto de Manuel Bandeira, e, para o segundo, as fotografias presentes no Guia Turístico de 2014 e as fotografias compartilhadas por turistas na rede social Instagram com a hashtag Ouro Preto. Essa análise permitiu comparar o quanto a imagem de Ouro Preto se modificou, como foi e é intensa a incorporação da cidade como produto de mercado e o quanto as representações da cidade seguem as transformações histórico-políticas.

Palavras-chave: Ouro Preto, Turismo, Representação.

\section{Abstract:}

Ouro Preto, as it is known today, had its importance increased throughout Brazilian history. The city's image has taken proportions that extrapolated the socio-economic scope, with the touristic scene as its great focus. Within this path, there are two events that deserve attention: with regards of having been the stage for political discussions upon the national Brazilian identity, initiated in the twentieth century with the modernist movement; and, also, having had light shed due to the development of tourism, consolidated from the second half of the same century. Thus, the goal the intention of the present study was to analyze the changes occurred in the representations of Ouro Preto in these two moments. For the first time were chosen the paintings of the artist Guignard and the drawings from the Guide to Ouro Preto from Manuel Bandeira, and, the second, the photography the 2014 tourist guide, as well as the photos shared by tourists on the Instagram social media with by the hashtag Ouro Preto. This analysis made it possible to compare how much the image of Ouro Preto changed, how intense the incorporation of the city as a product of the market was and how much the representations of the city follow the historical-political transformations.

KEYWORDS: Ouro Preto, Tourism, Representation.

\section{ReSUMEN:}

Ouro Preto, como se conoce hoy, fue adquiriendo importancia a lo largo de la historia de Brasil. La imagen de ciudad ganó proporciones que sobrepasan el ámbito histórico-social, teniendo como el gran enfoque el reclamo turístico. En ese recorrido, hay dos acontecimientos que merecen destaque aquí: fue el escenario de las discusiones sobre el carácter nacional brasileño, que se inició en el siglo XX con los modernistas; y también, evidenciarse por la formación del turismo, consolidado a partir de la segunda mitad del siglo XX. Frente a esto, la intención del presente estudio fue analizar los cambios ocurridos en las representaciones de Ouro Preto en esos dos momentos. Para el primer periodo fueran escogidas las pinturas del artista Guignard y los diseños del Guía de Ouro Preto de Manuel Bandeira, y para el segundo, las fotografías presentes en el Guía Turístico de 2014 y las 
fotografías compartidas por turistas en la red social Instagram con la hashtag Ouro Preto. Este análisis permitió comparar cuánto la imagen de Ouro Preto se modificó, como fue y es intensa la incorporación de la ciudad como producto de mercado y cuánto las representaciones de la ciudad siguen las transformaciones histórico-políticas.

Palabras clave: Ouro Preto, Turismo, Representación.

\section{INTRODUÇÃO}

O presente artigo tem como objetivo discutir a constituição de diferentes imaginários sobre a cidade de Ouro Preto. A trajetória de interesse para a pesquisa pode ser caracterizada por dois momentos de extrema relevância para a discussão sobre tal processo construído por diferentes olhares: a preocupação com a preservação do conjunto urbano, entendido como reflexo da nossa história e como representativo de uma identidade nacional desejada, defendida a priori pelos modernistas no século XX; e a sua consolidação em destino turístico, de grande importância para o circuito turístico mineiro que se convencionou nomear de "cidades históricas", com início mais relevante a partir da década de 1950 e intensificado hoje.

De maneira pontual, a estrutura do artigo se fundamenta, primeiramente, em contextualizar a cidade de Ouro Preto, desde sua formação até sua evolução como destino turístico, isso feito sob o viés da patrimonialização e do mercado turístico. Em relação às representações de Ouro Preto associadas ao processo que a tornou Monumento Nacional, a contextualização se constrói em torno do modernismo brasileiro e tem como destaque o Guia de Ouro Preto de Manuel Bandeira, com ilustrações de Luís Jardim, e o artista brasileiro Alberto da Veiga Guignard e suas pinturas de Ouro Preto. Já as representações da Ouro Preto Turística, baseiam-se na construção da cidade enquanto imagem para consumo do mercado e, nesse sentido, serão analisados o Guia de Ouro Preto de 2014 e as imagens que circulam na rede social Instagram com a hashtag Ouro Preto como um outro meio de difusão do turismo. Essas comparações se estruturam em dois olhares sobre o ponto de vista da experiência do sujeito e o seu processo perceptivo.

\section{TEMPOS DE OURO PRETO}

A cidade de Ouro Preto tem origem com as descobertas auríferas e remonta ao final do século XVII. Após a disseminação da fama do local e novas descobertas, há um grande crescimento de várias localidades, ou seja, novos arraiais, onde começam a surgir pequenos tipos de comércios e também edificações, iniciando um núcleo urbano. Nesse sentido, em 1711, os aglomerados urbanos existentes, como Ouro Preto, Antônio Dias e Padre Faria são unidos e dão origem a Vila Rica. A partir disso, com o sucesso da atividade mineradora, a região passa por um intenso processo de expansão urbana, principalmente entre as décadas de 1730 e 1760 . Ainda nos anos 1760, a atividade aurífera decai sobremaneira. Vila Rica deixa de ser o centro de referência econômica no País, mas, mesmo assim, em 1823 se eleva a capital da Província de Minas Gerais, passando a ser chamada de Ouro Preto.

A situação de Ouro Preto, nessa época, gerava um cenário decadente. Os estragos causados pela mineração faziam da cidade um conjunto sem coerência urbanística e malconservado, não tão agravado devido ao status de capital. Tal cenário perdurou algumas décadas e, em meio às diversas críticas, deixa de ser a capital de Minas Gerais passando, em 1897, seu posto a Belo Horizonte. Como aponta Andriolo (1999, p. 17), "tal data sintetiza as posições relativas ao século XIX e sobre a situação de desprestígio que envolvia Ouro Preto”. E mais, "a mudança da capital também era regida por um sentido estético, pelo qual as construções coloniais tornaram-se indignas de abrigar os poderes provinciais".

Belo Horizonte, cidade planejada aos moldes da modernidade, seria então o símbolo da República, sendo Ouro Preto vista como ultrapassada. Conforme explica Salgueiro (1996, p. 131), a decisão oficial de mudar a capital figura na Constituição Republicana Estadual de Minas Gerais de 1891 e reforça a crítica 
da falta de condições oferecidas por Ouro Preto para tornar-se uma capital moderna. Avenidas largas e grande planejamento urbano eram justamente características inviáveis para uma cidade como Ouro Preto, marcada por sua topografia acidentada e, consequentemente, por sua desordem urbana. "Era o símbolo de um tipo de formação urbana que deveria ser radicalmente alterado por estar associado ao atraso e à insalubridade" (AGUIAR, 2013, p. 180). A mudança da capital ocasionou graves problemas em Ouro Preto, principalmente pelo forte êxodo populacional. Abandono não só por parte da população em si, mas abandono político e administrativo, deixando a cidade mais decadente do que já estava mesmo antes dessa alteração. Foi uma fase de obscurantismo, na qual a cidade estaria fadada ao esquecimento.

Essa condição começa a se transformar com o surgimento das discussões, ideologicamente motivadas, sobre preservação de uma memória, de uma cultura, de um Brasil em diversas esferas. Ouro Preto, assim, passa a adquirir um papel de destaque por ser representante da história brasileira, devido a sua importância no caráter econômico durante o período colonial e no caráter político relacionado ao movimento da Inconfidência Mineira. Para tanto, a cidade não deveria entrar no processo de modernização sem se voltar para todo o passado que existiu, nem mudar sua condição material, mas deveria trazer as marcas de tal passado em seu traçado e em sua arquitetura.

Em fins do século XIX e começo do XX, Ouro Preto passa a assumir uma imagem cujo principal atributo seria sua imutabilidade como signo da preservação de uma memória histórica; de uma tradição que deveria ser mantida sob pena de perder um importante elemento constitutivo da identidade brasileira e mineira (NATAL, 2005, p. 6).

A cidade simbolizaria, então, as peculiaridades de uma memória coletiva. A relação com seu passado se altera: o que era para ser esquecido passa a ser valorizado. A cidade deve contar sua história por meio das edificações, monumentos e ruas.

Agora, ela não mais seria vista como uma cidade decadente, desordenada, decrépita ou vetusta, que deveria ser transformada, mas, ao contrário, torna-se a imagem de um passado heroico que deveria ser preservado da ação temporal (NATAL, 2007, p. 6).

Os discursos e ações que contribuíram para a criação de uma cidade histórica, com visão de patrimônio nacional têm na expedição modernista de 1924 um de seus marcos. Conhecida como viagem de redescoberta do Brasil, feita a Minas Gerais, incluía a cidade de Ouro Preto, cujo objetivo era "descobrir as origens da nacionalidade para se construir um país moderno" (HORTA, 2014, p. 114). A viagem lançou base para uma política preservacionista de cunho oficial, possibilitando ampliar o sentido do que se convencionou chamar de "cidade histórica".

A viagem foi composta por artistas, como Mário de Andrade, Oswald de Andrade e Tarsila do Amaral, que levavam o poeta franco-suíço Blaise Cendrars para conhecer um Brasil velado pelo progresso das capitais. Essa viagem foi de extrema importância, uma vez que representou a ascensão do enfoque nacionalista. Com isso,

Um novo olhar para a arquitetura colonial se afirmava [...]. Doravante, o legado artístico colonial passava a ser visto não como um estilo acabado, mas como produção híbrida, ou antes, popular, e a arquitetura barroca reinterpretada como universo aberto à intervenção de cristãos e pagãos, artistas e artesãos, europeus, ameríndios e africanos (SODRÉ, 2010, p. 73).

A aproximação com realidades diversas daquelas encontradas na cidade de São Paulo, a possibilidade do contato com o outro, o próprio questionamento de suas esferas de pertencimento, enfim, tais deslocamentos apresentam um caráter fortemente etnográfico, restabelecendo novas fronteiras entre as esferas (SODRÉ, 2010, p. 71).

A escolha de Minas Gerais, segundo Mário de Andrade, se deu em função da região ser palco de uma arte original devido ao isolamento. A distância em relação ao litoral fez com que, de certa maneira, deixasse de ser tão influenciada pela cultura portuguesa, possibilitando maior liberdade quanto à organização territorial e urbana. A peculiaridade da arquitetura religiosa, intensamente marcada aqui, também pode estar relacionada a essa questão. 
O barroco mineiro representaria para o autor de Macunaíma, por seu estilo, a verdadeira expressão artística nacional, por não importar elementos externos em seu plano arquitetônico, incorporando a própria decoração. O barroco mineiro seria, enfim, o primeiro estilo artístico da nacionalidade tupiniquim (HORTA, 2014, p. 119).

Sodré (2010, p. 71) ainda exemplifica por meio da obra de Mário de Andrade que o modernismo brasileiro, expresso na viagem modernista, aparece a partir da busca pelas características brasileiras consideradas legítimas e associadas à ideia da recuperação de um passado e uma tradição, cujos vestígios se encontravam diluídos na cultura popular, a partir da língua falada, da música e das artes plásticas.

O modernismo assumia a sua contradição essencial: na busca do novo, encontrava, através do velho, uma identidade genuinamente brasileira, encontrava uma tradição brasileira - no presente, o passado. À medida que o conjunto arquitetônico barroco era valorizado, a relação dos artistas brasileiros com o modelo europeu ia sendo revista (FRANCO, 2013, p. 212).

Com o sentimento de querer preservar essa identidade genuinamente brasileira presente no patrimônio mineiro, o grupo cria um plano para a formação de uma Sociedade dos Amigos das Velhas Igrejas de Minas Gerais, cujo objetivo seria a preservação das igrejas abandonadas. (FRANCO, 2013, p. 213).

Entretanto, o ideal de restabelecer a identidade brasileira a partir da valorização do passado artístico barroco se perdeu com a Revolução de 24 em São Paulo. Uma década depois, reapareceu e passou a tomar dimensões oficiais, isto é, em 1933, a cidade de Ouro Preto foi declarada Monumento Nacional. Essa ação se concretizou a partir da participação do grupo modernista no Ministério da Educação e Saúde Pública de Gustavo Capanema. Ocorreu, nesse encontro, um processo de criação de entidades governamentais responsáveis pela definição e proteção dos bens materiais que poderiam configurar o Patrimônio Histórico e Cultural do Brasil.

A aproximação dos ideais modernistas ao governo Vargas traz ao processo de patrimonialização de Ouro Preto outro significado. O discurso sobre parte da memória dos movimentos políticos (Inconfidência) obteve uma relevância maior, e o olhar sobre os vestígios materiais dos diferentes tempos, que encheu os olhos dos modernistas, passou por um processo de apagamento em favor da constituição de uma narrativa visual mais coerente com os investimentos simbólicos.

A criação dessa nova cidade contou, assim, com grande alteração na sua arquitetura, levando a uma conversão desse barroco mineiro no que ficou conhecido como "Estilo Patrimônio" (MOTTA, 1987). Porém, a forma urbana não sofreu muita alteração, seu traçado e seu tecido urbano são, de certa maneira, originais.

A política patrimonial de restauração, que contribuiu para fazer de Ouro Preto um mito, manteve a tendência de reproduzir certas formas eleitas como "autênticas", a fim de manter "a harmonia do conjunto". A cidade hoje mostra poucos traços da arquitetura doméstica extremamente simples, da época da corrida do ouro (SALGUEIRO, 1996, p. 127).

A partir dessa construção de imagem de cidade, Ouro Preto passa a ser entendida como uma obra de arte, no sentido de que ela não viria a sofrer grandes modificações e permaneceria inalterada. A consolidação de tal imagem foi um grande passo para a posterior construção de Ouro Preto como destino turístico. A formação da "cidade histórico-turística" se deu por meio de um longo processo que teve início, de fato, próximo da década de 1950, com a campanha "Salvemos Ouro Preto", e tem como desdobramento, após várias ações, a inscrição em 5 de setembro de 1980 na lista de Patrimônio da Humanidade da Unesco, a partir de esforços conjugados entre Estado e sociedade civil, com a ação de Aloíso Magalhães (MOTTA, 2008).

O cenário de culto à nação é não só o ponto de partida para a preservação da cidade, mas também proporcionou a elevação de Ouro Preto como bem simbólico e, consequentemente, como atrativo turístico. Assim, pode-se entendê-la como uma construção social. "A cidade é um artefato, produzido socialmente de modo complexo, em relação ao tempo e ao espaço” (ANDRIOLO, 2009, p. 160). 
Nesse sentido, fica evidente uma aproximação da questão patrimonial com o turismo, entendida entre outras maneiras, como um meio de melhorar a ação preservacionista, sendo que cada vez mais aumentam as verbas destinadas ao campo turístico.

Em diversos momentos observamos uma convergência de interesses entre as políticas preservacionistas e os projetos de desenvolvimento turístico da cidade, percebidos como a solução para muitos dos problemas que dizem respeito à salvaguarda do antigo conjunto urbano tombado em nível federal desde 1938 (AGUIAR, 2013, p. 189).

Do mesmo modo, a inserção da política se faz presente por meio da construção do caráter nacional de Ouro Preto. Os investimentos no setor turístico, juntamente com os desdobramentos na imprensa e nas agências de viagem, e projetos governamentais consolidam o produto turístico que conhecemos como cidades históricas mineiras (ANDRIOLO, 2009, p. 164), possibilitando perceber a cidade sobre os olhos de um turismo ideologicamente direcionado.

Na década de 1990, a política neoliberal implantada no País,

acabou por ser incorporada na vida contemporânea, ao transformar os núcleos históricos preservados em cenários para o consumo e para a satisfação das necessidades de lazer da sociedade. Assim, a difusão do turismo e a crescente valorização econômica dos bens culturais promoveram a consagrada união entre turismo e patrimônio cultural (OLIVEIRA; VITTE, 2004, p. 13).

Nesse percurso sobre a história dos investimentos simbólicos em Ouro Preto, percebemos então a cidade, que foi condenada a ser ruínas ao perder o posto de capital mineira, ser tomada como imagem, manifestação material, de diversos discursos. O percurso do esvaziamento dos verdadeiros sentidos dos caminhos e pedras pode ser notado nas relações de figuração das diferentes representações que se produziram desde então, como veremos a seguir

\section{OLHARES SOBRE OURO PRETO}

Ainda no início da criação do Serviço do Patrimônio Histórico e Artístico Nacional (Sphan), o diretor Rodrigo Melo Franco de Andrade encomenda à Manuel Bandeira o Guia de Ouro Preto. Por mais que o nome pressuponha uma atividade turística, difere bastante do que conhecemos hoje como algo que informe e seduza o turista. Naqueles escritos há uma mescla da história da cidade e sua formação com informações relevantes a quem viesse a conhecê-la. "Por sua ampla veiculação, Bandeira realizara a façanha de colocar em prática uma verdadeira educação patrimonial, contribuindo para a formação cultural da população brasileira de maneira acessível e didática” (UZÊDA, 2017, p. 27). Cabe ressaltar que Manuel Bandeira foi nomeado, pelo então ministro Gustavo Capanema, membro do Conselho Consultivo do Sphan, em 1938, e assumiu esse cargo até 1968, ano de sua morte. O Guia de Ouro Preto aparece como uma das medidas introdutórias em relação à inserção das questões preservacionistas à população.

Não deve ser lido apenas como guia turístico, pois representa um esforço de difusão dos critérios modernistas de preservação adotados pelo Sphan, que encarava a cidade de Ouro Preto como um bem patrimonial imóvel, isto é, como uma cidademonumento (FRANCO, 2013, p. 217).

Manuel Bandeira foi uma figura importante quando se refere às questões de preservação, não só por fazer parte do Sphan, mas também por atitudes e pensamentos que antecedem a criação de tal órgão responsável. "A preocupação de Bandeira com o patrimônio edificado de Ouro Preto e de outras cidades históricas de Minas Gerais passa sobretudo pela afetividade" (UZÊDA, 2017, p. 5). O poeta se encantou não só com Ouro Preto, mas com as outras cidades mineiras, com a riqueza histórico-arquitetônica brasileira que carregavam. Em 1928, na crônica intitulada "Defesa de Ouro Preto", Bandeira coloca:

Olinda, São Salvador e Ouro Preto deveriam constituir pontos de peregrinação obrigatória para todo o brasileiro que tenha o gosto da história social e artística do nosso passado. Pelo fato de haverem sido os núcleos densos da vida colonial em épocas 
de prosperidade e riqueza, elas fixaram mais do que as outras cidades do país o caráter da vida brasileira nos séculos XVII e XVIII. [...] Essa tradição é que cumpre zelar. Não permitir que os seus templos se arruínem [...]. Sobretudo não consentir nas restaurações depredadoras do velho caráter dos seus monumentos. A isso seria mil vezes de preferir a ruína, que destrói a matéria mas respeita a alma (BANDEIRA, 2008, p. 317-318 apud UZÊDA, 2017a, p. 42).

Nesse período, Luís Jardim, escritor e ilustrador pernambucano, trabalhava no Sphan junto com Manuel Bandeira, que o convidou para ilustrar o Guia de Ouro Preto. O artista já desenvolvia trabalhos de pesquisa na cidade mineira que envolviam a análise de obras por meio do redesenho que resultaram em dois artigos publicados na Revista do Sphan sobre a pintura colonial mineira, intitulados: A pintura decorativa em algumas igrejas antigas de Minas, de 1939, e A pintura do guarda-mor José Soares de Araújo em Diamantina, de 1940. Jardim já havia ilustrado um guia de cidade escrito por Gilberto Freyre, o Guia prático, histórico e sentimental da cidade do Recife de 1934. (NITA, 2010)

Envolvido com os esforços de preservação do patrimônio, seus desenhos revelam um olhar cuidadoso e atento aos mínimos detalhes. Em técnica de bico de pena, as ilustrações são marcadas pelo uso intenso de pontos. Com isso, os desenhos são mais pontuais, feitos ao nível da rua, e vêm complementar o que está sendo informado. Um conhecimento prévio para o leitor do que pode vir a conhecer, entretanto, construído por uma representação, a qual mostra que não é uma reprodução fiel da realidade, mas sim uma leitura do desenhador diante do observado e diante do que quer mostrar como resultado. A finalidade do desenho influencia na sua execução e, assim, o que aparece são desenhos minuciosos, em que cada detalhe pode vir a contribuir para informar o leitor, destacando a preciosidade da cidade mineira. Outra característica marcante dessa produção é o ponto de vista do passante que se vê sozinho em uma Ouro Preto sem habitantes. Um olhar próximo, mas nostálgico.

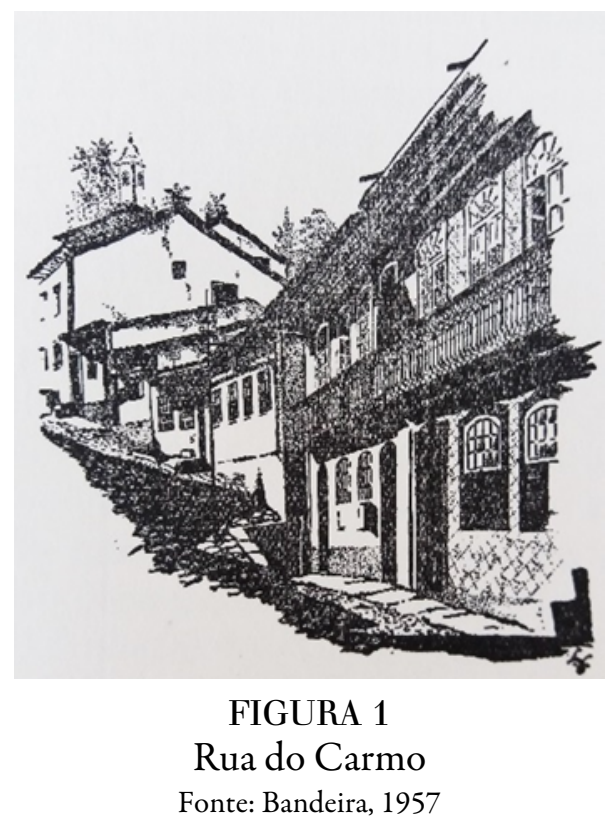

Manuel Bandeira é responsável pelo autor de um segundo olhar sobre essa imagem de Ouro Preto que se construiu no século XX. Em 1942 leva Alberto da Veiga Guignard (1896-1962) para conhecer a cidade, como descreve Pierre Santos, professor, crítico de arte e amigo do artista:

Guignard, quando esteve em Ouro Preto pela primeira vez, ficou embasbacado. Isso foi em 1942. Ele havia ganhado o Pre\#mio do Sala\#o Nacional, no Rio de Janeiro, e veio conhecer Minas. Foi o poeta Manuel Bandeira que o aconselhou: "Va\# pra Minas que tem tudo a ver com voce\#". Ma\#rio Sile\#sio conta que eles chegaram a\# noite em Ouro Preto, apo\#s o dia inteiro de viagem. Guignard, cansado, na\#o quis ver nada e foi dormir. No dia seguinte, acordou cedo e na\#o sabia dizer uma palavra, maravilhado com o que via. Enta\#o exclamou: "E\# isso que eu procurei a vida inteira. Eu quero viver e\# aqui" (SANTOS, 2003, p. 4) 
Manuel Bandeira, anos mais tarde, vai caracterizar esse olhar particular de Guignard sobre a paisagem de Ouro Preto:

[Em Minas] quem mais ganhou com a presença de Guignard foi Ouro Preto, que hoje está definitivamente tombada na obra do pintor [...] A Ouro Preto de Guignard não é triste, Guignard remoça Ouro Preto, sem no entanto a descaracterizar (BANDEIRA, 1986, p. 57).

A construção de Ouro Preto acerca das questões de preservação e valorização local, o primeiro dos dois momentos de importância para a pesquisa, obteve grande contribuição aqui

Los discursos nacionalistas que enraizaron a la ciudad de Ouro Preto en el imaginário brasileño encontraron importantes mediaciones en los trazos de Tarsila do Amaral y las pinturas de Alberto da Veiga Guignard. A partir de ellas el paisaje de la ciudad histórica fue concebido en oposición a los dos centros urbanos en expansión en el país. (ANDRIOLO, 2008, p. 182).

Compreender a contribuição particular de Guignard para uma visão de Ouro Preto, por meio do resgate / criação de um passado colonial significativo, é uma ação de pesquisa que passará necessariamente por um olhar mais atento à sua trajetória e suas opções estéticas, aqui inicialmente mapeado.

Nos anos de 1940, dentro do projeto de revolução cultural colocado em ação na capital mineira, está a “criação da Escola Guignard, símbolo, também, da deselitização da cultura artística no Estado, com a ascensão da classe média na sociedade industrial. Em especial, o lugar para o crescimento das experiências humanas no cotidiano da cidade" (VIEIRA, 1988, p. 17). Nesse contexto, o Curso Livre de Desenho e Pintura ministrado pelo artista instaurava uma nova ordem cultural-artística na capital (VIEIRA, 1988). Na opinião do artista plástico Miguez (2009, p. 207), Guignard produzia uma pintura a se esvair, despertando um interesse muito maior do que os caminhos consagrados pela academia.

Tinha um modo peculiar de ensinar: antes de começar o desenho, os alunos tinham que aprender a ver. Era preciso ter atenção no agora, "a observação da realidade exterior com a interioridade de cada um, possibilitava o despertar da liberdade criadora” (ANDRÉS, 1996, p. 319).

Por mais que Guignard seja moderno, há nele algo que é singular. Pode ser considerado moderno por seu caráter nacionalista, característica intrínseca ao discurso da arte moderna no Brasil, pela busca do que é nativo. No entanto, o artista vai para além disso, consegue conciliar essa qualidade com algo que vem de uma tradição, muitas vezes associada à sua infância.

Seus trabalhos sugerem uma assimilação gradual da linguagem moderna, produzindo assim uma obra na qual parecem se mesclar duas temporalidades, dois espaços, um ainda ligado à tradição e o outro decididamente moderno. Ou, em outras palavras, uma modernidade que é construída por uma via de mão dupla, em que não se nega o passado, mas se procura atualizálo, no sentido mais potente da palavra (PALHARES, 2010, p. 20).

A tradição, que em parte provém da sua infância, pode ser claramente observada em suas paisagens difusas. Por mais que elas tenham um certo tom onírico, ou ainda, como diz Naves (1996, p. 133), um aspecto lavado, onde o mundo parece prestes a escorrer, como se o víssemos através de uma janela molhada, elas são pontuadas por pequenos ritmos que remontam a elementos presentes quando era criança. São balões, igrejas, pessoas, palmeiras, que se aproximam das recordações de festas juninas, festas de São João. E, por consequência, aproximam do nosso país, da nossa identidade. "É a esses pequenos seres que cabe conseguir uma caracterização para as paisagens desoladas. Torná-las Ouro Preto e não uma simples região fantasma" (NAVES, 1996, p. 141). 


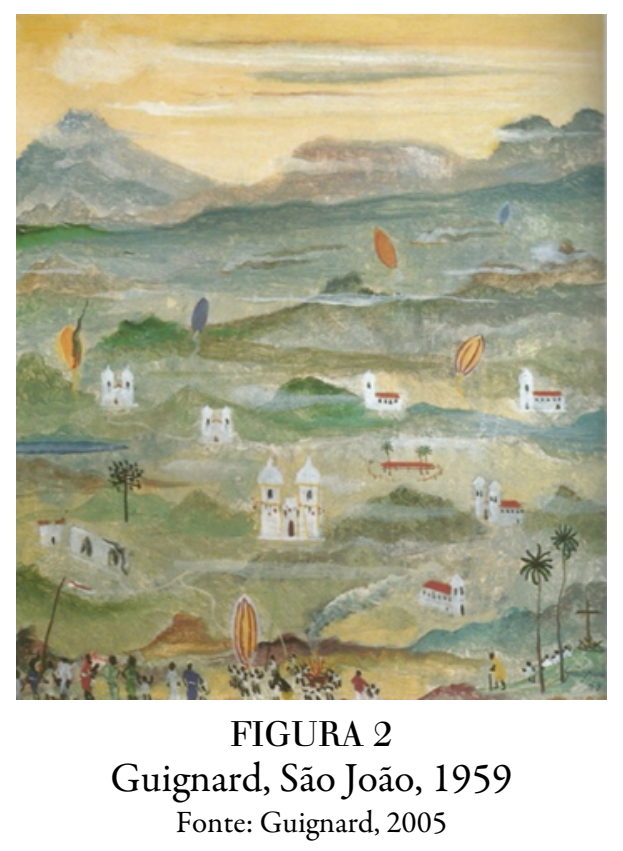

A grande questão se molda em torno da construção do campo plástico proposto por Guignard, da maneira com que as representações são enquadradas e o que enquadram. É possível perceber que Guignard parte do todo, parte da leitura da paisagem até chegar em algo mais detalhado e que dá vivacidade ao quadro, como igrejas, pessoas e balões. O que mais lhe chama atenção é a topografia de Ouro Preto e que ele a traduz como algo onírico por se associar a sua experiência, a sua memória, a sua infância. Nessa aproximação, aparece o cuidado com o popular, um popular do Brasil, como ação de resgate da nossa tradição como brasileiros, a qual é também uma tradição do próprio autor. Isso é uma tradução do período, do papel do modernismo no País e sua defesa de uma identidade supostamente nacional. Em muitas obras de Guignard a tradição vem com a festa de São João, o povo se reúne no cenário criado por Guignard e isso possibilita uma dinâmica que se contrapõe à calmaria da paisagem natural.

Esses dois primeiros olhares sobre Ouro Preto, entre muitos outros do mesmo período, revelam duas experiências de aproximação ao conjunto de edificações históricas. São olhares oriundos de duas vivências diferentes: Luís Jardim com o olhar do pesquisador que busca guardar algo preciso deslocado em seu tempo histórico; Alberto Guignard em um olhar afetivo que busca na atualização das tradições locais o que lhe toca, o que torna o lugar visitado mais que a manifestação concreta de um discurso de glória ao passado.

Tais contribuições não foram só para os desdobramentos preservacionistas diante da cidade histórica, como também para o início do que veio a se constituir Ouro Preto como cidade turística e, consequentemente, fomentar a produção de uma outra qualidade de representação, ou seja, os Guias Turísticos.

Aparece, então, a difusão da imagem fotográfica supostamente documental, pela sua proximidade com a realidade figurada. Esse conjunto de imagens é incorporado aos documentos visuais da cidade histórica, criando assim um cenário mais propício para o turismo e também "um modelo para a percepção do turista" (ANDRIOLO, 2009, p. 164).

Como se vê atualmente, o grande meio de divulgação do turismo é a imagem. As belas imagens de pontos específicos da cidade fazem com que o turista já contemple o lugar antes mesmo de conhecê-lo, ou melhor, contemple a cidade de uma maneira que não é real, e sim distorcida. É a “invenção e a mitificação da realidade e dos lugares, por parte da mídia e dos agentes de viagem, para que eles possam ser vendidos previamente, como uma mercadoria turística, de exploração simbólica, imediata e superficial” (OLIVEIRA; VITTE, 2004, p. 8). 
Em consequência disso, vê-se uma cidade construída no imaginário do turista e esperada como tal por ele. Em outras palavras, a divulgação do lugar turístico cria uma expectativa para o turista, o qual vai em busca do lugar que lhe foi mostrado. Conforme Oliveira e Vitte (2004, p. 8), o movimento turístico torna-se pobre e superficial porque esse turista-consumidor não deseja reflexão, introspecção, envolvimento ou dúvidas, realiza, apenas, uma leitura superficial do espaço. (Error 1: La referencia debe estar ligada) (Error 2: El tipo de referencia es un elemento obligatorio) (Error 3: No existe una url relacionada)

A resposta sobre isso aparece na forma de novas imagens, agora geradas pelo olhar desse turista. Ao tentar encontrar o que procura, por meio da sua percepção sobre o espaço já condicionada, muitas vezes o turista acaba por reproduzir o que conhece de antemão. Isso pode ser observado nas imagens compartilhadas nas redes sociais. Com a utilização de filtros, de ferramentas que criem uma nova aparência para a imagem, o resultado final parece se assemelhar muito ao que é encontrado nos produtos vendidos pelas agências e guias turísticos. É instaurado um processo de reprodução de imagens superficiais, por meio do qual o turista é afastado da experiência do lugar visitado.

Quanto à relação entre o Guia de 2014 e as fotos da rede social Instagram feitas por turistas, e indexadas como \#ouropreto, pode-se notar a semelhança entre os tipos de representação. Semelhança no que representar, no enfoque dado a certos edifícios e espaços, como se fosse uma espécie de proposição e resposta. Os guias, de modo geral, propõem uma visita, propõem um percurso determinado ao visitar a cidade, enquadrando o que foi criado para o consumo, consequentemente, de modo mais pontual, são as famosas igrejas, os monumentos, os museus, as atrações que são consideradas históricas.

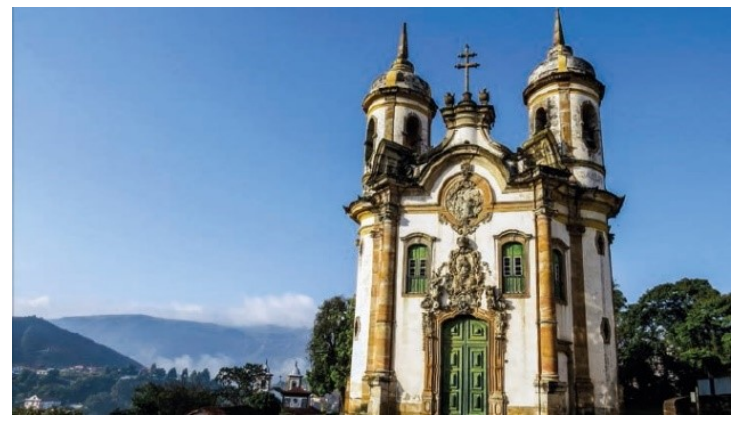

FIGURA 3

Igreja de São Francisco de Assis.

Fonte: Guia Turístico de Ouro Preto, 2014

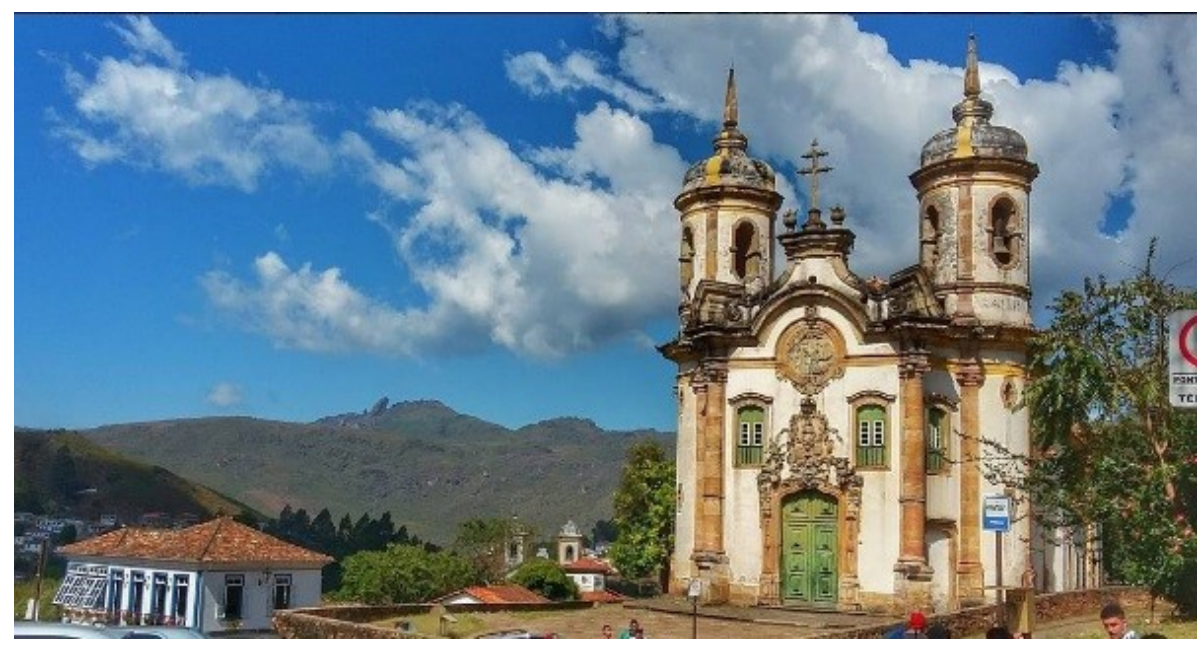

FIGURA 4

Igreja de São Francisco de Assis

Fonte: \#ouropreto, Instagram, 2016 
As fotos compartilhadas no Instagram podem ser lidas como uma resposta ao que é mostrado. O uso dos recursos digitais de captura de imagem, como filtros e simulações de lentes, transforma as fotos de modo que pareçam com o que foi comprado a priori. Nesse sentido, as representações acabam se repetindo quanto a enquadramento, a pontos de vistas e, assim, se tornam esvaziadas. $\mathrm{O}$ turista não possui mais a liberdade de apreender com a sua própria experiência; seu ato perceptivo parece já estar condicionado. Podemos entender que é essa, justamente, a intenção dos guias turísticos: levar o turista a algo predeterminado, a uma experiência segura marcada por uma sensação de conforto.

O turista se insere nessas representações por meio das selfies, como aquele que está presente em seu papel de espectador passivo da cena re-encenada. As imagens não revelam um pertencimento afetivo com o ocorrido, mas apenas a justaposição de presenças. O turista e a festa, o turista e a cidade.

\section{REFLEXÕES SOBRE AS IMAGENS DE OURO PRETO}

A pesquisa buscou identificar questóes a partir da experiência do sujeito e do seu modo de apreender o que observa. Isso porque, ao representar, o sujeito seleciona involuntariamente alguns elementos em detrimentos a outros por meio do seu ato de perceber. O que lhe é essencial aparece em destaque e o que não lhe chamou atenção, desaparece (MASSIRONI, 1996). Com isso, nota-se que cada representação é particular e que depende de cada processo perceptivo. Andriolo (2009, p. 162) cita Lowe (1986) dizendo que em cada período a cultura dos meios de comunicação forja um ato de perceber, e que o sujeito fica delimitado por uma diferente organização hierárquica dos sentidos. Assim, o campo perceptivo constituído é uma formação histórica que difere entre um período e o seguinte.

Nesse sentido, foi possível aproximar e distanciar os tipos de representação com base em questões relevantes para a compreensão do que foi e do que é Ouro Preto e de como diferentes acontecimentos conduziram o caminho para chegar até a cidade histórico-turística. De início, uma busca pela identidade nacional e pela preservação desse nacional, e, posteriormente, sua transformação em destino turístico. Selecionar a fase do modernismo, da patrimonialização como inicial foi uma estratégia para comparar o quanto Ouro Preto se modificou e como foi e é intensa a incorporação da cidade como produto de mercado.

Além disso, a transformação de Ouro Preto, enquanto cidade e enquanto representação dessa cidade, seguiu as transformações históricas e políticas. Cada contexto político refletiu na configuração das imagens de Ouro Preto e o contexto da política neoliberal foi o que alterou radicalmente o cenário urbano. Isso adveio de uma série de consequências que culminou com o que conhecemos de Ouro Preto: fortemente baseada na comercialização do turismo histórico-cultural. O que proporciona essa comercialização? Justamente as imagens que circulam na mídia, as que foram destacadas neste estudo. "O que fundamenta os produtos turísticos e a sua comercialização no mercado é um conjunto de imagens que representam lugares e coisas" (ANDRIOLO, 1999, p. 5).

A intenção e os pontos de vista diante do que é a cidade diferem nos casos aqui apresentados. No primeiro caso, cidade patrimônio, vê-se uma aproximação maior com a cidade em si, com o que Ouro Preto tem a oferecer naturalmente para a nossa apreciação, para a nossa percepção. Enquanto que no segundo caso, cidade turística, com base na produção de mercado, a cidade perde seu significado inicial e passa a ser mais um produto a ser comercializado. Com a comercialização e difusão de determinadas imagens, já temos na memória o que é Ouro Preto e, mais, o que esperar de Ouro Preto.

A questão que se coloca é que Ouro Preto é apenas um de muitos exemplos que foram incorporados pela indústria cultural. Hoje, é difícil visualizar com clareza o que significa Ouro Preto ser turística de um ponto de vista que não seja o econômico. Segundo Fonseca (2007, p. 4), "a estratégia fundamental do sistema cultural assenta na exploração de todas as possibilidades para prender a atenção do público-alvo, fazendo crer que todo e qualquer acontecimento é relevante devido à sua divulgação". De modo geral, os espaços que antes tinham 
uma função definida - O que era um museu? O que era um parque? O que era uma cidade? - hoje parecem não terem mais. Parecem que se transformaram unicamente em espetáculos, cuja função é gerar lucro.

\section{REFERÊNCIAS}

AGUIAR, L. B. Cidade morta, cidade monumento, cidade turística: a construção de memórias sobre Ouro Preto. In: História do Turismo no Brasil. Rio de Janeiro: FGV, 2013, p. 180-193.

Alberto da Veiga Guignard, 1896-1962. Rio de Janeiro: Edições Pinakotheke. Catálogo de Exposição. Max Perlingeiro (Apresentação). Pinakotheke (Organização), 2005.

ANDRÉS, M. H. Guignard, o mestre. Estudos Avançados (USP), São Paulo, v. 10, n. 28, p. 319-330, 1996.

ANDRIOLO, A. Ouro Preto, 1897-1973: a construção social de uma cidade histórica turística. São Paulo: Dissertação de Mestrado, FAU-USP, 1999.

. Entre a ruína e a obra de arte: psicossociologia da percepção da cidade histórica turística. Estudos de Psicologia, UFRN. Natal, v. 14, p 159-166, 2009.

Actividad pictórica y imagen percibida: la ciudad histórico-turística de Ouro Preto. Estudios y Perspectivas en Turismo. Buenos Aires, v. 17, n. 1-2, p. 170-184, enero-abril, 2008.

BANDEIRA, M. Guia de Ouro Preto, 3. ed. Rio de Janeiro: Ministério da Educação e Saúde, 1957.

Ouro Preto remoçada, 2. ed. In:

Andorinha, Andorinha. Rio de Janeiro: José Olympio, 1986.

FONSECA, R. P. P. A arte no mercado: seus discursos como utopia, n. 6. E-topia: Revista Electrónica de Estudos sobre a Utopia, 2007.

FRANCO, M. A. Ouro Preto dos poetas modernistas. Remate de Males. Campinas, v. 33, n. 1-2, p. 211-224, jan.dez. 2013.

HORTA, O. M. M. Mário de Andrade e os modernistas em Minas Gerais no reconhecimento da tradição para a identidade nacional. Miguilim: Revista Eletrônica do Netlli, v. 3, n. 2, p. 113-124, maio/ago. 2014.

MASSIRONI, M. Ver pelo desenho: aspectos técnicos, cognitivos, comunicativos. Rio de Janeiro: Edições 70, 1996.

MOTTA, L. O Sphan em Ouro Preto: uma história de conceitos e critérios. In: Revista do Patrimônio Histórico e Artístico Nacional. Rio de Janeiro: Ministério da Cultura / Fundação Nacional Pró-Memória, 1987, p. 108-122.

. Ouro Preto: de Monumento Nacional a Patrimônio Mundial. In: SORGINE, J. et al. Salvemos Ouro Preto: a campanha em benefício de Ouro Preto, 1949/1950. Rio de Janeiro: Iphan, Copedoc, 2008, p. 12-17.

NATAL, C. M. Imagens de Ouro Preto: a construção de uma cidade histórica, 1891-1933. In: XXIII SIMPÓSIO NACIONAL DE HISTÓRIA. HISTÓRIA: GUERRA E PAZ, 2005, Londrina- PR. Anais ... 2005.

Ouro Preto: a construção de uma cidade histórica, 1891-1933. Dissertação (Mestrado) - Departamento de História do Instituto de Filosofia e Ciências Humanas da Universidade Estadual de Campinas, Campinas, 2007.

NAVES, R. A Maldade de Guignard. In: MUSEU LASAR SEGALL. Guignard: uma seleção da obra do artista. São Paulo: Secretaria Municipal de Cultura/Prefeitura do Município de São Paulo, 1992, p. 11-14.

O Brasil no ar: Guignard. In: NAVES, R. A Forma Difícil: ensaios sobre arte brasileira. São Paulo: Editora Ática, 1996, p. 131-143.

NITA, M. R. F. Jogo de espelhos: a ilustração e a prosa de ficção de Graciliano Ramos, Jorge Amado e José Lins do Rego. Tese (Doutorado). Campinas: Instituto de Artes da Universidade Estadual de Campinas, 2010.

OLIVEIRA, M. R. S.; VITTE, C. de C. O fenômeno turístico e suas implicações na cidade de Ouro Preto. In: II ANPPAS - ENCONTRO DA ASSOCIAÇÃO NACIONAL DE PESQUISA E PÓS-GRADUAÇÃO EM AMBIENTE E SOCIEDADE, Indaiatuba, 2004. Anais ... 2004.

PALHARES, T. H. P. Modernidade, tradição e caráter nacional na obra de Alberto da Veiga Guignard. Tese (Doutorado). FFLCH-USP, São Paulo, 2010.

SAlgueiro, H. A. Ouro Preto: dos gestos de transformação do "colonial" aos de construção de um "antigo moderno". Anais do Museu Paulista, São Paulo, v. 4, p. 125-63, jan/dez. 1996. 
Ana Laura Assumpção, et al. Olhares sobre Ouro Preto: da Patrimonialização ao cenário turístico

SANTOS, P. Passos de Guignard em Ouro Preto (entrevista). Projeto Guinard. 2003. Disponível em: http:// www 1.cultura.mg.gov.br/fronteira/template/entrevista/pierre_santos.pdf $>$..

SODRÉ, J. C. A. Arquitetura e viagens de formação pelo Brasil 1938-1962. São Paulo: Dissertação (Mestrado). FAU-USP, 2010.

UZÊDA, A. L. M. de. Crônicas de um passado que verdadeiramente nos pertence: memória e patrimônio em Manuel Bandeira. EntreLetras (On-line). Araguaína-TO, v. 8, 2017, p. 24-49.

VIEIRA, I. L. A Escola Guignard na cultura modernista de Minas 1944 - 1962. Pedro Leopoldo, MG: Companhia Empreendimento Sabará, 1998.

CC BY 